\title{
Skin impedance
}

\author{
John G. Webster ${ }^{1,2}$ \\ 1. Department of Biomedical Engineering, University of Wisconsin, Madison WI 53706 USA \\ 2. E-mail any correspondence to: webster@engr.wisc.edu
}

Most measurements in bioimpedance yield a fixed reproducible result. But I always liked to work on bioimpedance of the skin because it is so challenging. It is important to know the impedance of the skin when measuring the electrocardiogram because if your amplifier input impedance is not high enough, undesirable attenuation will occur. A typical skin impedance is about $500 \mathrm{k} \Omega$ for 1 $\mathrm{cm}^{2}$. But Rosell et al. [1] showed that at $1 \mathrm{~Hz}$ there is a wide spread for different subjects from $10 \mathrm{k} \Omega$ to $1 \mathrm{M} \Omega$. And as the frequency increases to $1 \mathrm{MHz}$, impedance decreases to about $300 \Omega$. Then impedance changes with time.

Olson et al. [2] showed that impedance decreases steadily or exponentially with time constants of several hours. Lozano et al. [3] note that impedance varies with body location and is much lower on the tongue than elsewhere on dry skin. Bahr et al. [4] show that impedance decreases from $1 \mathrm{M} \Omega$ to $200 \mathrm{k} \Omega$ in 1 min during a hot flash. De Talhouet et al. [5] showed that impedance drops from $500 \mathrm{k} \Omega$ to $5 \mathrm{k} \Omega$ after 12 skin strippings using Scotch tape.

If you calculate the skin impedance under a defibrillator electrode you get $500 \mathrm{k} \Omega / 100 \mathrm{~cm}^{2}=5 \mathrm{k} \Omega$. But after defibrillation if you remeasure you get $50 \Omega$. What has happened is the high defibrillator voltage has arced through the skin and created many holes that lower the impedance and redden the skin. There are a variety of subject areas if you want to further explore skin impedance.

\section{References}

1. Rosell, J., J. Colominas, P. Riu, R. Pallás-Areny, and J. G. Webster, Skin impedance from $1 \mathrm{~Hz}$ to $1 \mathrm{MHz}$, IEEE Trans. Biomed. Eng., 35, 649-651, 1988. http://dx.doi.org/10.1109/10.4599

2. Olson WH, Schmincke DR, Henley BL Time and frequency dependence of disposable ECG electrode-skin impedance. Med Instrum. 1979 Sep-Oct;13(5):269-72.

3. Lozano CA1, Kaczmarek KA, Santello M Electrotactile stimulation on the tongue: Intensity perception, discrimination, and cross-modality estimation. Somatosens Mot Res. 2009 Jun;26(2):50-63. http://dx.doi.org/10.1080/08990220903158797

4. Bahr, D. E., J. G. Webster, D. Grady, F. Kronenberg, J. Creasman, J. Macer, M. Shults, M. Tyler and X. Zhou, Miniature ambulatory skin conductance monitor and algorithm for investigating hot flash events, Physiol. Meas. 35, 95-110, 2014. http://dx.doi.org/10.1088/0967-3334/35/2/95

5. de Talhouet, H., and J. G. Webster, The origin of skin-stretchcaused motion artifacts under electrodes, Physiol. Meas., 17, 81-93. 1996. http://dx.doi.org/10.1088/0967-3334/17/2/003 